\title{
Animacy, Frequency and Working Memory Effects in the Acquisition of a Noun-Adjective Agreement Pattern in L2 under Incidental Learning Conditions
}

\author{
Nadiia Denhovska ${ }^{1}$ \\ ${ }^{1}$ School of Psychology, University of Central Lancashire, UK \\ Correspondence: Nadiia Denhovska, School of Psychology, University of Central Lancashire, UK. E-mail: \\ ndenhovska@uclan.ac.uk
}

Received: June 17, 2016 Accepted: July 10, 2016 Online Published: September 23, 2016

doi:10.5539/ijel.v6n5p12 URL: http://dx.doi.org/10.5539/ijel.v6n5p12

\begin{abstract}
Animacy is recognized as an important feature in cognition and language processing. The present paper reports the results of an experiment that investigated the effects of animacy of the head noun (animate, denoting animals-epicenes, and inanimate, denoting non-living objects) and working memory on the learning of a noun-adjective agreement pattern in Russian. Participants were 60 novice learners whose L1 did not mark grammatical gender. The between-subjects design manipulated token frequency (high vs. low) under incidental learning conditions. No animacy effect was found in either learning condition. Working memory was a significant factor in both incidental learning conditions, and it explained a greater amount of variance in the high token frequency condition where accuracy was also significantly higher than in the low token condition. The results have implications for incidental learning research and language learning practices, specifically how different factors contribute to the acquisition of L2 grammatical knowledge.
\end{abstract}

Keywords: animacy, frequency, incidental learning, L2 grammar, working memory

\section{Introduction}

Research in cognitive science demonstrated that animate entities are processed more efficiently than inanimate entities, as they attract more attention (Lipp, Derakshan, Waters, \& Logies, 2004; Öhman, Flykt, \& Esteves, 2001; Öhman, Lundqvist, \& Esteves, 2001). Individuals detect features of humans and animals more quickly and accurately than of inanimate objects (New, Cosmides, \& Tooby, 2007; Kirchner \& Thorpe, 2006). Animacy is also an important cue for learning of gender agreement patterns (Alarcon, 2009; Sagarra \& Herschensohn, 2011). Therefore, when learning takes place via incidental exposure, there are grounds for thinking that animacy might be a significant contributor to the acquisition of grammatical knowledge: it is a salient feature of the input that can be attended to during learning without intention and explicit instruction. Previous research on implicit learning demonstrated that some learning is possible under incidental learning conditions (Lee, 2002; Leung \& Williams, 2011; Rebuschat \& Williams, 2012). However, it still remains unclear what factors contribute to the successful acquisition of a natural L2 grammar via incidental exposure. The aim of the present paper was to investigate how the animacy of the head noun affects the acquisition of the noun-adjective agreement pattern in Russian under incidental learning conditions where token (high versus low) frequency was manipulated. Additionally, we assessed the role of working memory in learning of the agreement pattern where gender is not explicitly marked (i.e., when it does not match the natural gender of the head noun).

\subsection{Animacy as a Salient Feature for Language Learning}

Animate entities are more semantically rich, and therefore are memorized more quickly (Hargreaves, Pexman, Johnson, \& Zdrazilova, 2012). Experimental memory research uncovered an animacy effect, i.e., the fact that animate referents are remembered better than inanimate referents (VanArsdall, Nairne, Pandeirada, \& Blunt, 2013). VanArsdall, Nairne, Pandeirada, \& Blunt (2013) presented participants with pairs including a living or a non-living referent and a novel word that denoted such a referent. They tested participants' memory for living and non-living referents and found that non-words paired with properties of living things were recalled faster and more accurately than the ones paired with properties of non-living things.

In a series of experiments Bonin, Gelin, \& Bugaiska (2013) used an incidental encoding task with verbal and 
pictorial stimuli to investigate the animacy effect on memory and the quality of the recognition. Animate words were categorized faster than inanimate words in a recall task. A similar effect was found for pictures identifying animate or inanimate entities. Words denoting animate entities also evoked a different response related to the different quality of memorization compared to words denoting inanimate entities. Thus, in a task where participants had to say whether they recognized a word and indicate whether their responses were based on remembering, knowing or guessing animate entities generated more responses based on remembering. In an eye-tracking study Yang, Wang, Yan, Zhu, Chen, \& Wang (2012) measured participants' eye movements during viewing pictures of animals and inanimate objects having negative or neutral emotional valence. They found that non-human animals were more likely to be attended to and for longer than inanimate objects

Some researchers posit that animate concepts are remembered better than inanimate concepts, because animates represent a more accessible category than inanimates (VanArsdall, Nairne, Painderaida, \& Cogdill, 2014). In a paired-associate learning of foreign words study VanArsdall et al. (2014) paired Swahili words with animate and inanimate items and asked participants to learn the English translations of the Swahili words; in another experiment with a similar design they selected animate and inanimate English words belonging to the categories of four-legged animals and furniture. It was found that targets paired with animate words were recalled much more accurately than the ones paired with inanimate words. Animate concepts related to animals and humans are thought to be more accessible because they are perceptually salient stimuli in the environment (New, Cosmides, \& Tooby, 2007; Pratt, Radulescu, Guo, \& Abrams, 2010) and that the distinction between what is animate and what is inanimate develops very early in life (Opfer \& Gelman, 2011). The implications of the aforementioned research are especially relevant to the present study, as it outlines how the animacy feature might help the learning of the morphological pattern pertinent to an animate versus an inanimate item.

Research on processing of gender agreement in L2 also demonstrated a positive animacy effect. Some researchers believe that gender agreement is easier to process with animate nouns when the grammatical gender of the noun corresponds to the natural gender of the referent (Antón-Méndez, 1999; Vigliocco \& Franck, 1999; Finnemann, 1992). Others argue that gender agreement with animate nouns is more difficult to process because the noun may evoke two counterparts in both masculine and feminine gender, for example, esposo (m)/esposa (f) "spouse" in Spanish (Bruhn de Garavito \& White, 2002).

Sagarra \& Herschensohn (2011) investigated whether adult second language learners of Spanish are sensitive to gender congruency between the adjective and the noun, a grammatical feature not present in their native language (English), and to the noun animacy. Intermediate learners and native monolingual speakers performed better than beginners in terms of accuracy and $R T \mathrm{~s}$ on agreement structures with inanimate (where gender assignment is arbitrary) rather than animate nouns (where grammatical gender matches natural gender). Animacy was not a significant factor in the processing of animate versus inanimate nouns for beginners. These findings suggested that processing the agreement with animate head nouns was more cognitively demanding for learners with higher proficiency levels, possibly due to the fact that an animate noun in one gender might had activated its counterpart in another gender, which however was not the case for beginner learners. Beginner learners, whose native language did not have grammatical gender marking, did not receive a sufficiently large amount of input to develop knowledge of gender agreement and were not in a position to rely on transfer from their first language during the task.

In contrast, Alarcon (2009), who explored processing of Spanish gender agreement using an online comprehension task in native speakers and L2 learners, found that animacy was a strong cue for choosing the correct agreement form and that adjective-noun agreement for animate head nouns whose grammatical gender correlated with natural gender was processed faster than the agreement with inanimate head nouns. Similarly, Sagarra \& Herschensohn (2012) found a significant animacy effect on processing cost of gender agreement in Spanish: sentences involving agreement with animate head nouns were processed faster than with inanimate.

The finding that animacy had a positive effect on syntactic processing was also confirmed by Jackson \& Roberts (2010) focusing on the comprehension of relative clauses in L2 Dutch by native speakers of German using self-paced reading. Researchers investigated how subject versus object relative clauses (RCs) were processed when the animacy of the antecedent noun phrase (NP) and the RC-internal NP was manipulated. Clauses with animate subjects were rated more acceptable than those with inanimate subjects by both L2 learners and native speakers. The processing of inanimate subject RCs also elicited longer reading times than animate subject RCs. In addition, there was no preference for subject over object RCs if the subject was animate.

The aim of the present paper was to study whether animacy as a salient perceptual feature played a role in the acquisition of a gender agreement pattern by beginner learners. We intended to understand whether animacy 
facilitated the acquisition of a gender agreement pattern where the grammatical gender of animate nouns did not have a natural gender correlate. Unlike previous research on gender agreement, we did not include nouns denoting animates whose grammatical gender matched their natural gender (e.g., devochka "girl"/malchik "boy", kuritsa "hen"/petuh "rooster"). The rationale behind this choice was to explore whether the learners could acquire gender in a new language solely on the basis of the changing morphological pattern of endings between the two grammatical genders (masculine, feminine), rather than immediately associating the paradigm of endings in a particular gender with its explicitly marked male or female referent.

\subsection{Token Frequency}

Research on first language acquisition has a long-lasting tradition in considering frequency as an influential factor in language learning (implicit acquisition of L1 in children) (Abbot-Smith, Lieven, \& Tomasello, 2004; Kidd, Lieven, \& Tomasello, 2006, 2010; Lieven \& Tomasello, 2008; Matthews et al., 2005; Tomasello, 2003). Token frequency is important since it plays a role in entrenchment by helping to register the specific items of a given construction in memory as exemplars. Proponents of cognitive-associative view on second language posit that the same principles apply to L2 grammar learning (Gass \& Mackey, 2002; N. Ellis, 2002). Nevertheless, little research directly compared the impact of frequency on the incidental acquisition of grammatical knowledge in a natural L2 unfamiliar to learners, especially in different modalities - production vs. comprehension. Robinson (2005) had shown that high token frequency had some positive effect on memorization of grammatical constructions during comprehension of a natural L2, since learners were able to memorize old, but failed to transfer knowledge to the new items. In our previous study we found a strong positive effect of token frequency on productive knowledge acquisition under incidental exposure (Denhovska, Serratrice, \& Payne, 2016). However, in that experiment as tokens of a noun-adjective agreement construction we used items that included nouns whose referents were marked for biological gender (e.g., witch/magician). In the present study we were interested whether the same impact of frequency would be kept for items that do not have correspondence with natural gender.

\subsection{Working Memory and L2 Grammar}

Regarding the acquisition of L2 knowledge in incidental learning conditions, one important issue to address is the role of working memory (WM) (defined as "the system for temporarily storing and processing information while performing higher order cognitive tasks such as comprehension, learning and reasoning" (Baddeley \& Logie, 1999)). Learning under incidental exposure is more dependent on other contributing factors because learners are not directly provided with explanations underlying the regularities in the input. Understanding of the contribution of different factors, including working memory, may, therefore, inform second language learning research and would help to improve L2 classroom instruction practices.

Previous research focusing on WM in second language acquisition (Alptekin \& Ercetin, 2009; Harrington \& Sawyer, 1992; Hummel, 2009; Juffs, 2004; Kempe, Brooks, \& Kharkhurin, 2010; Leeser, 2007; Masoura \& Gathercole, 2005; Speciale, N. Ellis, \& Bywater, 2004; Tagarelli, Borges Mota, \& Rebuschat, 2011) provided mixed results regarding the relation of WM to L2 learning, specifically learning through incidental exposure.

Generally SLA research showed that WM was positively correlated with L2 grammar learning. Williams \& Lovatt (2003) focused on how individual differences in phonological memory influence the ability to learn determiner-noun agreement rules on the basis of gender in a semi-artificial language and found a significant positive correlation with WM. Sagarra \& Herschensohn (2010) who studied the role of language proficiency and WM in the acquisition of the adjective-noun agreement in Spanish using self-paced reading found a positive WM effect in intermediate learners for detecting grammatical gender agreement violations. Sagarra (2007) showed similar effect in English-Spanish beginner learners.

Nevertheless, research dwelling on working memory and learning under incidental exposure generally found no correlation with WM (Brook \& Kempe, 2013; Tagarelli et al., 2011). Yang \& Li (2012) explored the neural cognitive mechanisms underlying the implicit and explicit learning of artificial grammar sequences and measured participants' working memory using the N-back task. In line with previous research, they found the impact of WM on the grammaticality judgements of the AG sequences in the explicit, but not in the implicit learning condition.

Similarly, no effect of working memory was found in research by Tagarelli et al. (2011) who studied the role of working memory in receptive knowledge acquisition of L2 syntax in a semi-artificial language under incidental and explicit learning (rule-search) conditions. The correlation was found in the rule-research, but not in the incidental learning condition. A null effect of WM on productive knowledge acquisition was also uncovered in the study by Brooks \& Kempe (2013). The study investigated the acquisition of productive knowledge of 
Russian gender and case agreement patterns by novice learners through incidental exposure over six sessions. Given this set of findings, it is important to further investigate whether working memory would be engaged in the learning of grammatical agreement in incidental learning conditions. Particularly, we explored the effect of working memory during learning of an agreement pattern where gender was not explicitly marked and where the change in the morphological pattern did not depend on the animacy or the natural gender of the stimulus item which may create a more cognitively demanding task for learners.

\subsection{The Present Study}

In the present study we investigated whether animacy played a significant role in the receptive and productive knowledge acquisition of the noun-adjective agreement in Russian as a function of case and gender under incidental learning conditions. Participants were novice learners with no prior exposure to Russian from a range of L1 backgrounds, none of which included a language with grammatical gender. In addition to the role of animacy, we investigated the role of token frequency and of working memory. The role of token frequency in acquisition of grammatical knowledge had been emphasized by many usage-based theorists regarding first (Tomasello, 2000, 2008) and second (N. Ellis, 2002, 2006) language acquisition. The effect of high token frequency was stressed in relation to exemplar-based learning; repeated exposure and the use of a given construction leads to the accumulation of a critical mass of tokens and to subsequent entrenchment. Therefore, consistently with previous research we expected that high token frequency would facilitate better knowledge retention of the target grammatical structure when learning through incidental exposure. In addition, the relevance of working memory during language exposure in incidental learning conditions is still poorly understood (Brooks \& Kempe, 2013; Tagarelli et al., 2011) and one of the aims of the study was to investigate it further. The questions of the present study are:

1) What is the role of token frequency in the acquisition of receptive and productive knowledge of a noun-adjective agreement pattern under incidental learning conditions?

2) Does the noun's animacy have a differential impact on knowledge acquisition of the agreement pattern in the comprehension and production domains?

3) Is working memory involved in the acquisition of receptive and productive knowledge of the agreement pattern (with head nouns whose grammatical gender does not correspond with biological sex) under different incidental learning conditions?

\section{Design}

We investigate the impact of the animacy of the head-nouns adjectival phrases, the frequency of exposure to the stimuli, and working memory on the acquisition of receptive and productive knowledge of the Russian noun-adjective agreement pattern according to gender and case. Stimuli were presented to the participants under two incidental learning conditions where token frequency was manipulated (high token, low token frequency) and an explicit learning condition.

The aim of the studywas to explore whether WM would be more or less engaged depending on the incidental learning condition with high or low token frequency involvement. In addition, we wanted to explore whether different animacy levels (animals versus inanimate objects) would play a role in knowledge retention. In the agreement pattern the animacy of the noun was manipulated (living vs. non-living), but the head noun's grammatical gender in either category did not match the natural gender; the change in the morphological pattern was also not dependent on animacy. Therefore, we were interested whether the pattern would be memorized and generalized to new items better in the agreement with animate compared to inanimate nouns in accordance with previous research (VanArsdall et al., 2013).

In the incidental learning conditions of the present study we adopted the training paradigm normally used in the literature for learning morpho-syntax under the incidental exposure. Conditions in which participants were focused on meaning and were not informed about subsequent testing or given the actual grammatical rules were designed (Rebuschat \& Williams, 2012; Tagarelli et al., 2011). Learning taking place under such conditions is different from learning under rule-search (explicit) conditions where learners are informed about the existence of rules in the input and are instructed to figure them out (Tagarelli et al., 2011). Previous research demonstrated that an explicit learning condition is generally more effective for the acquisition of L2 grammar compared to incidental ones (DeKeyser, 1995; N. Ellis, 1993; Norris \& Ortega, 2000; Robinson, 1996). Therefore, an explicit learning condition was included in our study for the purposes of a baseline-comparison. We used metalinguistic explanations of the rule as a method of training in the explicit learning condition rather than using a rule-search condition which still allows for a degree of implicitness during learning. 


\subsection{Participants}

Sixty undergraduate students (15 male and 45 female; age range: 18-20) at a large university were included in the study. Participants were first year first semester students of Humanities; they signed a written consent form and received $7 \%$ course credit for their participation. All participants were native speakers of English. Following Leung \& Williams (2011), we excluded individuals with advanced knowledge of a second language. None of the participants had ever studied Russian or any other Slavic language and none of them had any advanced knowledge of a language marking grammatical gender.

\subsection{Materials}

The materials of the study were Russian words ( 6 animate nouns, 6 inanimate nouns, 12 adjectives, the 3 prepositions $k$, ot, $s$ "towards, away from, with", and the particle eto "this"). These words were embedded into sentences containing noun-adjective strings (see Table 1).

Table 1. Examples of training sentences

\begin{tabular}{|c|c|c|}
\hline Case & Masculine & Feminine \\
\hline \multirow[t]{2}{*}{ Nominative } & Eto beliy krolik-This is a white rabbit & Eto malaya belka-This is a small squirrel \\
\hline & $\begin{array}{l}\text { Eto } \quad \text { bel-iy } \\
\text { krolik-Ø } \\
\text { This Ø-cop } \quad \text { white-MASC.NOM } \\
\text {-MASC.NOM }\end{array}$ & $\begin{array}{l}\text { Eto } \quad \text { mal-aya } \\
\text { This Ø-cop } \quad \text { small-FEM.NOM } \\
\text { squirrel-FEM.NOM }\end{array}$ \\
\hline \multirow[t]{2}{*}{ Dative } & Idu k belomu kroliku- I am going towards the white rabit & Idu k maloy belke- I am going towards the small squirrel \\
\hline & 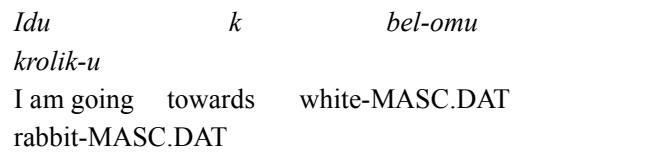 & $\begin{array}{lcc}\text { Idu } & k & \text { mal-oy } \\
\text { belk-e } & & \\
\text { I am going } & \text { towards } & \text { small-FEM.DAT } \\
\text { squirrel-FEM.DAT } & \end{array}$ \\
\hline \multirow[t]{2}{*}{ Instrumental } & Idu s belim krolikom- I am going with the white rabbit & Idu s maloy belkoy- I am going with the small squirrel \\
\hline & $\begin{array}{llc}\text { Idu } & s & \text { bel-im } \\
\text { krolik-om } & & \\
\text { I am going with } & \text { white-MASC.INST } \\
\text { rabbit-MASC.INST } & & \end{array}$ & $\begin{array}{llc}\text { Idu } & s & \text { mal-oy } \\
\text { belk-oy } & & \\
\text { I am going with } & \text { small-FEM.INST } \\
\text { belk-FEM.INST } & & \end{array}$ \\
\hline \multirow[t]{2}{*}{ Genitive } & $\begin{array}{l}\text { Idu ot belogo krolika- I am going away from the white } \\
\text { rabbit }\end{array}$ & $\begin{array}{l}\text { Iduotmaloybelki- I am going away from the small } \\
\text { squirrel }\end{array}$ \\
\hline & $\begin{array}{lcr}\text { Idu } & \text { ot } & \text { bel-ogo } \\
\text { krolik- } a & & \\
\text { I am going } & \text { away from } & \text { white-MASC.GEN } \\
\text { rabbit-MASC.GEN } & & \\
\end{array}$ & $\begin{array}{lrr}\text { Idu } & \text { ot } & \text { mal-oy } \\
\text { belk- } i & & \\
\text { I am going } & \text { away from } & \text { small-FEM.GEN } \\
\text { squirrel-FEM.GEN } & & \end{array}$ \\
\hline
\end{tabular}

The training sentences included noun-adjective agreement in feminine and masculine genders in nominative, dative, instrumental and genitive cases. Each slide contained a picture and a Russian sentence, such as the one presented in Figure 1. 


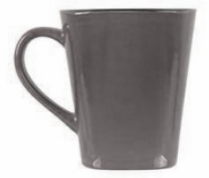

Eto krasnaya chashka
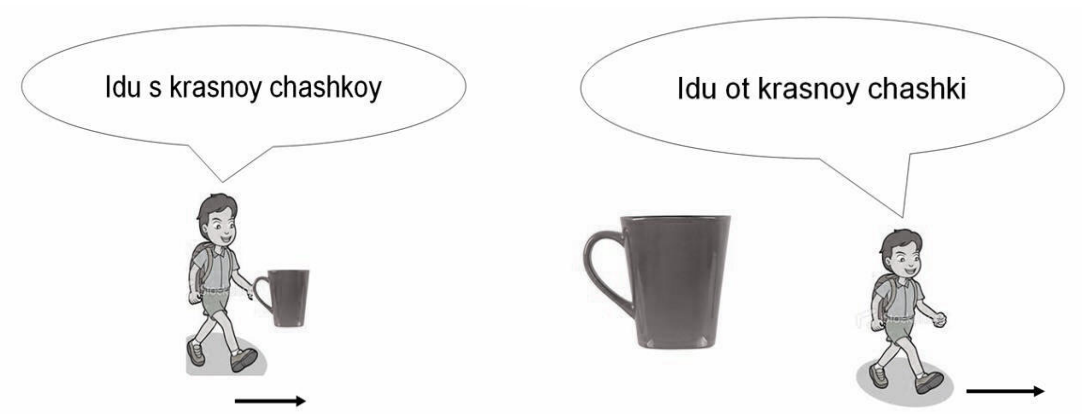

Figure 1. Example of training slides in incidental learning conditions

Table 2. Case-marking paradigm for feminine and masculine genders in Russian

\begin{tabular}{|c|c|c|c|c|}
\hline \multirow[b]{2}{*}{ Case } & \multicolumn{2}{|c|}{ Masculine gender } & \multicolumn{2}{|c|}{ Feminine gender } \\
\hline & Adjective & Noun & Adjective & Noun \\
\hline Nominative & -iy & $-\varnothing$ & -aya & $-a$ \\
\hline Dative & -omu & $-\mathrm{u}$ & -oy & $-\mathrm{e}$ \\
\hline Instrumental & $-\mathrm{im}$ & -om & -oy & -oy \\
\hline Genitive & - ogo & $-\mathrm{a}$ & -oy & $-i$ \\
\hline
\end{tabular}

We used adjectives that could be easily identified in the context of the pictures (e.g., small, white, old). Nouns contained 2-3 syllables and all adjectives were disyllabic. Half of the nouns were feminine and half masculine; the animate nouns were animals-epicenes whose grammatical gender in Russian did not correspond to any attribution of natural gender to the referent in English (e.g., slon "elephant" (m) or vidra "otter" (f)). The items were selected on the basis of preliminary ratings by independent raters. Fifty native speakers of English not participating in the experiment identified the item as male or female on the basis of their intuitions. The items included in the study as stimuli were equally likely to be considered as identifying a feminine or a masculine referent. Only nouns and adjectives that fell into the inflectional paradigm for case represented in Table 2 were selected.

Participants were presented with three types per each gender (masculine, feminine) and animacy category (animate, inanimate). Depending on the incidental learning condition, participants viewed a different number of tokens and thus a different number of experimental slides. Each type was represented by a story about an animal-epicene or an object. A story consisted of four sequential slides, which represented a noun-adjective agreement in one of four cases. The presentation of each story was randomized. The number of types and slides in each condition are presented in Table 3. 
Table 3. Distribution of types and tokens in incidental learning conditions

\begin{tabular}{llllllc}
\hline Incidental learning conditions & Gender & $\begin{array}{l}\text { Masculine } \\
\text { gender }\end{array}$ & Cases & Animacy & Repeated & Number of slides \\
\hline High token frequency & 3 types & 3 types & 4 cases & animate & 7 times & 336 slides \\
& 3 types & 3 types & 4 cases & inanimate & & 144 slides \\
Low token frequency & 3 types & 3 types & 4 cases & animate & 3 times & \\
& 3 types & 3 types & 4 cases & inanimate & & \\
\hline
\end{tabular}

\subsubsection{Working Memory Tests}

Participants completed two WM tasks delivered via E-Prime 2 (Psychology Software Tools, Pittsburgh, PA), Operation Span (OS) and Reading Span (RS) (Unsworth, Heitz, Schrock, \& Engle, 2005).

\subsection{Procedure}

Participants were randomly assigned to the explicit learning condition or one of the two incidental learning conditions. The experiment consisted of two working memory tests, pre-training, training and testing phase. In the pre-training participants learned new vocabulary and performed a test. It was followed by a training phase, in which participants either received explicit instruction on the noun-adjective agreement rule or were exposed to varying tokens of sentences in an incidental learning condition. Finally, the test phase immediately followed the training phase and participants were tested on their receptive and productive knowledge of noun-adjective agreement.

\subsubsection{Vocabulary Pre-training}

Participants memorized 6 Russian nouns, 4 adjectives, 3 prepositions ( $k$ "towards", ot "away from", $s$ "with") and the particle eto "this is" while going over the slides on the computer screen at their own pace. During vocabulary test in E-Prime they were presented with a picture and a Russian word transliterated into the Latin alphabet and had to press a corresponding key on the keyboard to indicate whether the word matched the picture. After their response, either the word "Correct" or "Incorrect", together with the overall percentage score, appeared on the computer screen. Participants had to score at least $85 \%$ on the vocabulary test to proceed to the training phase.

Also, during pre-training participants in the incidental learning conditions saw one sequence of pictures with Russian sentences for a stereotypical character of masculine gender (e.g., a magician), and one sequence of pictures with a stereotypical character of feminine gender (e.g., a witch). The participants were presented with translations of the sentences, but were not informed about case marking and were not told that inanimate nouns and animals-epicenes follow the same inflectional paradigm.

\subsubsection{Training}

During training participants viewed similar sequences of pictures depicting animals-epicenes and objects to those presented during pre-training. Each sequence represented a story, similar to the one represented in Figure 1, and consisted of four slides corresponding to the agreement pattern in the four cases. The four slides within a story were presented sequentially for $4000 \mathrm{~ms}$ each, in the following order: nominative, dative, instrumental and genitive case (see Figure 1 and Table 2). Participants received the following instructions: "Now you will see stories about different characters similar to the ones you have just seen. Please, look at the picture, read the sentence to yourself and try to understand its meaning". They were also not informed about the subsequent testing. There were two incidental learning conditions: low token frequency and high token frequency condition. Depending on the condition, participants were presented with a different number of tokens and thus a different number of experimental slides. The number of types and slides presented to the participants in each condition are presented in Table 3.

In the explicit learning condition participants received a metalinguistic explanation of the agreement rules on the basis of one example for a masculine and a feminine agreement pattern including stereotypical characters (e.g., magician, witch) as head nouns. They were explicitly told that that the agreement paradigm was the same for objects and animals, were given the picture with the corresponding gender for each item and were asked to memorize the gender, and informed that they would be tested on the agreement rule afterwards. They were then given 15 minutes to memorize the gender of each item and to look thorough the slides again at their own pace to learn the agreement rule. Each slide contained a Russian sentence transliterated into the Latin alphabet with adjectival and noun endings highlighted in bold, an English translation written underneath, and a semantically corresponding picture similar to the ones presented to participants in the incidental learning conditions. 


\subsubsection{Testing}

In the test phase participants performed a recognition task for comprehension and a fill-in-the-blank task for production. In the recognition task participants were presented with a picture of an object or an animal for $1000 \mathrm{~ms}$. A Russian sentence similar to the ones seen in training with a noun-adjective agreement pattern in either nominative, dative, instrumental or genitive case immediately followed the picture. The sentences appeared for $3000 \mathrm{~ms}$ on the computer screen. Participants were told that the sentence described the item presented in the picture. Participants were asked to press the corresponding key on the keyboard as quickly as possible, to identify whether the sentence referred to a masculine or a feminine item. They were instructed to focus on the sentence, not the picture, while making their judgments. The pictures of the objects and animals were presented in order for the participants to understand what the given sentence was about. We wanted to test whether there would be a relationship between participants' responses in terms of accuracy and $R T$ s depending on whether the sentential stimulus was about an animate or inanimate item. We expected that participants' responses in terms of feminine-masculine judgments would be based solely on the morphological pattern, since we previously controlled the pictorial stimuli and only selected items (objects and animals-epicenes) that did not show any masculine or feminine gender bias as judged by independent raters. In the explicit learning condition, participants were allowed to look at the pictures of items with their grammatical gender in Russian written underneath when completing the tasks.

The production task was a "fill-in-the-blank" task. Participants saw pictures with Russian sentences similar to the ones they were exposed to during training and had to provide the missing ending of the adjective. In both, the comprehension and production, tasks there were 28 grammatical Russian sentences ( 14 new and 14 old). There were 14 items with animate head nouns of each gender ( 7 of masculine and 7 of feminine) and 14 items with inanimate head nouns of each gender.

Before testing, participants in the incidental learning conditions were told that they would next see sentences and pictures similar to the ones they had seen previously, whereas participants in the explicit learning condition were told that they would be tested on the previously learned rule.

\section{Results}

We measured accuracy and $R T$ responses on old and new items for the two genders (masculine, feminine), four cases (nominative, dative, instrumental and genitive) and two levels of animacy (animate, inanimate) in the Recognition comprehension task and accuracy in "fill-in-the-blank" production task. The data were analysed using logistic and linear regression models in R (R Development Core Team, 2015), version 3.2.3. We checked for normality and homogeneity by visual inspections of plots of residuals against fitted values. Throughout the paper, we present MCMC-estimated p-values that are considered significant at the $\alpha=0.05$ level. We selected the variables on the basis of stepwise forward model, likelihood ratio tests $(\alpha=0.05)$, BIC criterion and theoretical importance.

The first aim was to explore the general levels of knowledge of receptive and productive knowledge of the given pattern acquired by participants under incidental learning conditions. We were also interested in how the manipulation of the token frequency (high vs low) would affect the levels of knowledge obtained under such training conditions. The results indicated that participants in the incidental learning conditions performed at chance level (see Figure 2), however participants in the baseline-comparison explicit learning condition performed slightly above chance (NB. in our previous experiment where head nouns indicating stereotypical characters whose grammatical gender correlated with biological gender were used, performance in all conditions was at ceiling). In production, participants performed below chance (see Figure 3).

\subsection{Acquisition of Receptive Knowledge of the Agreement Pattern}

To analyze accuracy in comprehension (performance on the Recognition task) the following factors were included in the model as fixed effects: Condition, OS Total score and RS Total score. These variables were included in the model on the basis of possible models comparison using the BIC criterion. The variable of Condition had three levels (explicit learning, low token frequency, high token frequency). The binomial family of the GLM with logit link function was employed. First, low token frequency was chosen as a reference category for the analysis, because of its theoretical interest; subsequently, the reference category was changed to the explicit learning condition in order to ensure that all learning conditions were compared with each other. The analysis showed a significant difference between conditions in comprehension accuracy of the noun-adjective agreement pattern. Participants in the explicit learning condition performed significantly better than participants in both incidental learning conditions, but there was no difference between the two incidental learning conditions (see Tables 4 and 7). 
Table 4. Analysis of participants' accuracy responses on the recognition task

\begin{tabular}{lllll}
\hline & Estimate & $\begin{array}{l}\text { Standard } \\
\text { Error }\end{array}$ & $\begin{array}{l}\text { Wald } \\
\mathrm{z}\end{array}$ & $p$ \\
\hline (Intercept) & -7.63 & 2.72 & -2.81 & .005 \\
\hline Condition: & & & & .48 \\
\hline low token frequency vs. high token frequency & 8.46 & 1.21 & .70 & $<.001^{* * *}$ \\
low token frequency vs. explicit learning & 4.03 & 1.22 & 3.30 & .99 \\
Operation Span Total & 1.37 & 5.07 & $2.69 .007^{* *}$ & \\
Reading Span Total & 3.83 & 4.67 & .01 & \\
\hline
\end{tabular}

Note. ${ }^{*} p<.05,{ }^{* *} p<.01, * * * p<.001$.

The mean scores in percentages representing general performance of participants on the Recognition task are presented in Figure 2. There was a significant effect of working memory for receptive knowledge acquisition.

Table 5. Analysis of participants' reaction time responses on the recognition task

\begin{tabular}{lllll}
\hline Error & Estimate & Standard & t value & $p$ \\
\hline (Intercept) & & & & 14.07 \\
\hline Condition: & 1169.86 & 83.16 & & $<.001$ \\
\hline low token frequency vs. high token frequency & 13.13 & 37.52 & .35 .73 & \\
low token frequency vs. explicit learning & 39.47 & 37.54 & 1.05 & .29 \\
Operation Span Total & -3.93 & 1.56 & -2.53 & $.01^{*}$ \\
Reading Span Total & 3.15 & 1.44 & 2.19 & $.03^{*}$ \\
\hline
\end{tabular}

Note. ${ }^{*} p<.05, * * p<.01,{ }^{* * *} p<.001$.

To analyze $R T s$ the same model as used for the analysis of accuracy was employed, but the Gaussian family of GLM (which is like OLS regression) with the identity link function was selected, because the response variable was continuous. No significant difference between the learning conditions in $R T$ s of comprehension of the noun-adjective agreement pattern was found (see Tables 5 and 7). However, similarly to comprehension accuracy, our analysis indicated a significant effect of working memory on $R T$.
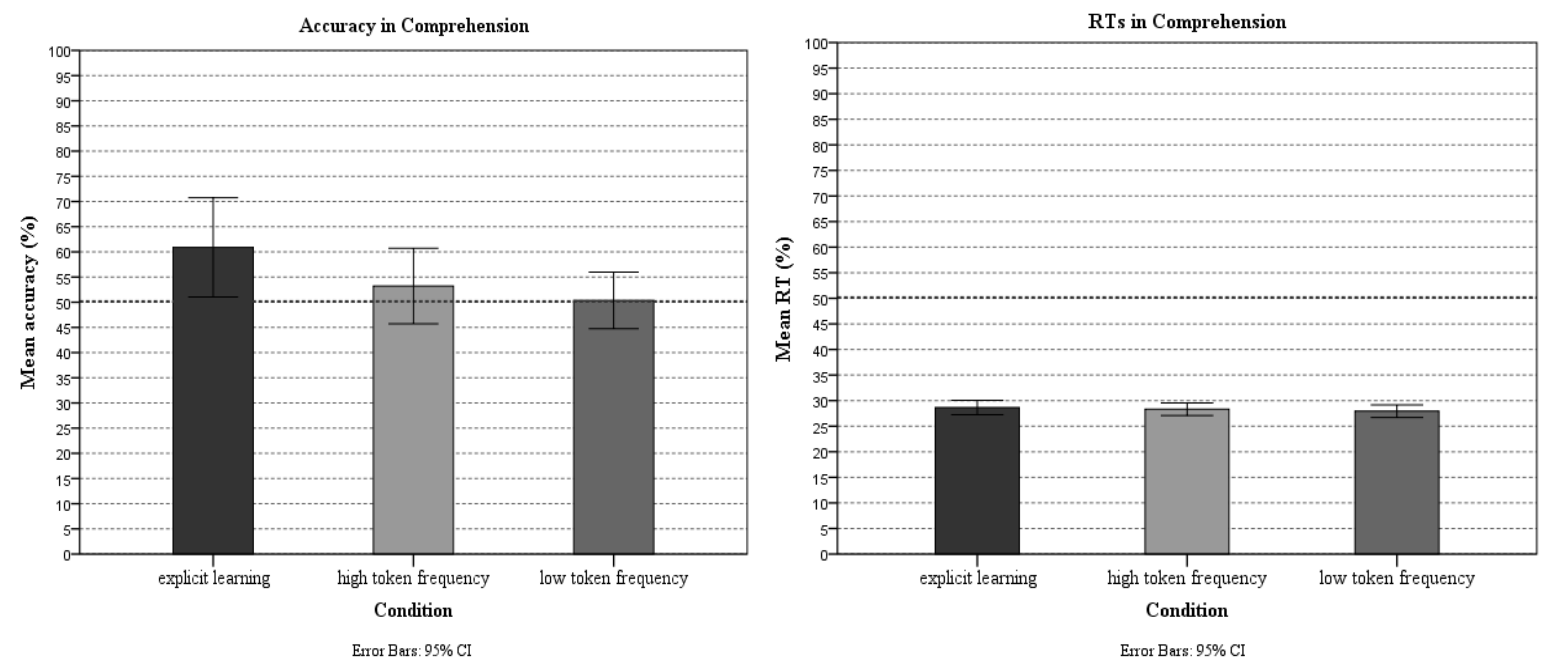

Figure 2. Accuracy and $R T \mathrm{~s}$ in percentages on the Recognition task in explicit learning and incidental learning conditions

\subsection{Acquisition of Productive Knowledge of the Agreement Pattern}

To analyse the production accuracy of adjectival endings in all conditions the same model was employed as was used for the analysis of comprehension accuracy. Condition, OS Total score and RS Total score were included in the model as fixed effects. The analysis indicated a better performance in the explicit learning condition than in 
both incidental learning conditions; participants in the high token frequency condition also performed significantly better than in the low token frequency condition (see Table 6).

Table 6. Analysis of participants' accuracy in production of complete endings on fill-in-the-blank task

\begin{tabular}{lllll}
\hline & Estimate & $\begin{array}{l}\text { Standard } \\
\text { Error }\end{array}$ & $\begin{array}{l}\text { Wald } \\
\mathrm{z}\end{array}$ & $p$ \\
\hline (Intercept) & -3.19 & .38 & -8.34 & $<.001$ \\
\hline Condition: & & & & \\
\hline low token frequency vs. high token frequency & .47 & .15 & 3.05. & $002^{* *}$ \\
low token frequency vs. explicit learning & 1.48 & .15 & 10.20 & $<.001^{* * *}$ \\
Operation Span Total & .02 & .01 & 3.28 & $<.001^{* * *}$ \\
Reading Span Total & .00 & .01 & .85 & .40 \\
\hline
\end{tabular}

Note. ${ }^{*} p<.05,{ }^{* *} p<.01,{ }^{* * *} p<.001$.

The mean production accuracy levels in percentages per condition are presented in Figure 3. As can be observed in the figure, participants in the explicit learning condition exhibited higher levels in production than participants in the incidental learning conditions.
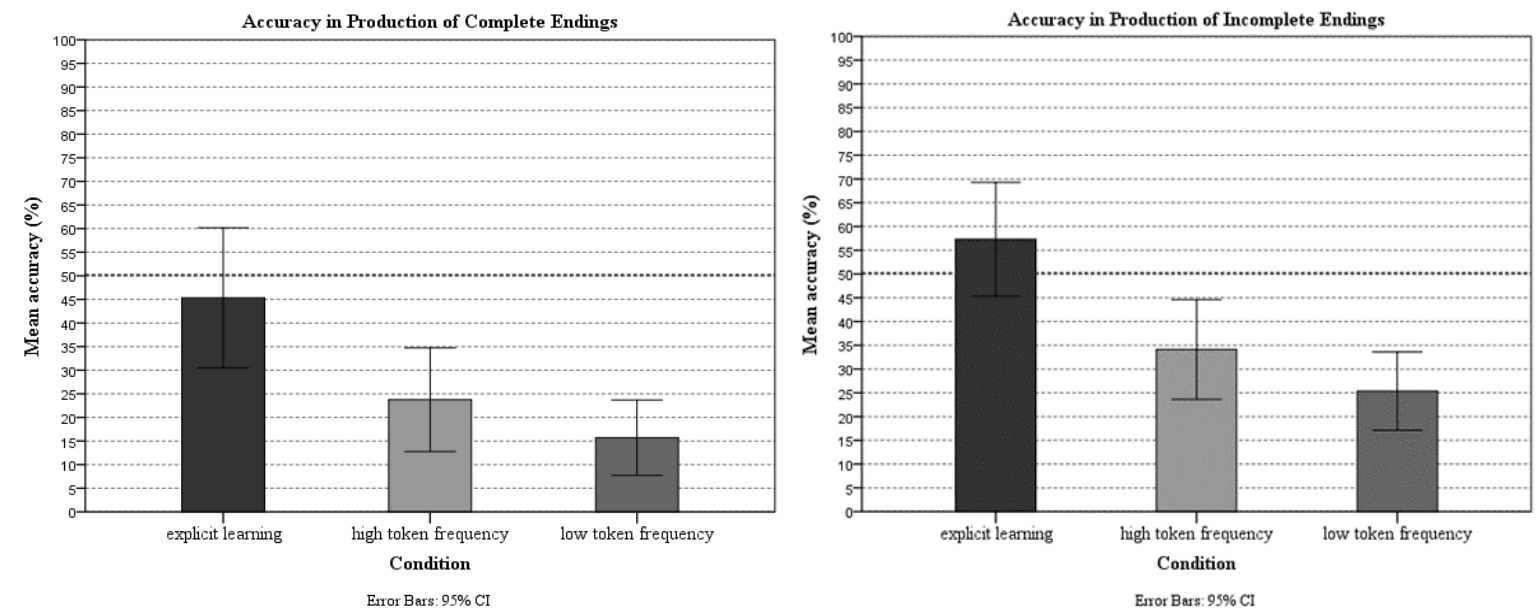

Figure 3. Accuracy in production of complete and incomplete endings on fill-in-the-blank task in explicit learning and incidental learning conditions

An analysis of production of incomplete endings was also conducted. For instance, if a participant did not produce the whole ending, but produced correctly one or two letters of the endings (e.g., instead of -aya for an adjective in feminine gender nominative case, $-y a$ or $-a$ was given), they received a score. Similarly to the production of complete endings, participants in the explicit learning condition had higher levels of productive knowledge than participants in the incidental learning conditions.

The same model was employed for the analysis of incomplete endings as used for complete endings. The variables of Condition, OS Total score and RS Total score were included in the model as fixed effects. A significant difference in performance between the incidental learning conditions was found, with participants in the high token frequency condition performing significantly better than in the low token frequency condition. (Note 1) Participants in the explicit learning condition also performed significantly better than in both incidental learning conditions (see Table 8). 
Table 7. Comparison between explicit learning and high token frequency condition

\begin{tabular}{|c|c|c|c|c|c|c|}
\hline \multicolumn{7}{|l|}{ Comprehension } \\
\hline \multirow[b]{2}{*}{ Explicit learning vs. } & \multicolumn{3}{|l|}{ Accuracy } & \multicolumn{3}{|l|}{$R T$} \\
\hline & Std. Error & Wald z & $p$ value & Std. Error & t value & $p$ value \\
\hline \multirow{3}{*}{$\begin{array}{l}\text { High token frequency } \\
\text { Production }\end{array}$} & 1.23 & -2.59 & $.01 *$ & 37.74 & -.69 & .49 \\
\hline & & & & & & \\
\hline & \multicolumn{3}{|c|}{ Complete accuracy } & \multicolumn{3}{|c|}{ Incomplete accuracy } \\
\hline Explicit learning vs. & Std. Error & $\mathrm{z}$ wald & $p$ value & Std. Error & z wald & $p$ value \\
\hline High token frequency & .13 & -7.59 & $<.001 * * *$ & .13 & -8.83 & $<.001 * * *$ \\
\hline
\end{tabular}

Note. ${ }^{*} p<.05, * * p<.01, * * * p<.001$.

Table 8. Analysis of participants' accuracy in production of incomplete endings on fill-in-the-blank task

\begin{tabular}{lllll}
\hline & Estimate & $\begin{array}{l}\text { Standard } \\
\text { Error }\end{array}$ & $\begin{array}{l}\text { Wald } \\
\mathrm{z}\end{array}$ & $p$ \\
\hline (Intercept) & -2.04 & .30 & -6.72 & $<.001$ \\
\hline Condition: & & & & \\
\hline low token frequency vs. high token frequency & .33 & .12 & 2.68 & $.007^{* *}$ \\
low token frequency vs. explicit learning & 1.47 & .13 & 11.30 & $<.001^{* *}$ \\
Operation Span Total & .01 & .01 & 2.45 & $.01^{*}$ \\
Reading Span Total & .01 & .00 & 2.49 & $.01^{*}$ \\
\hline
\end{tabular}

Note. ${ }^{*} p<.05, * * p<.01,{ }^{* * *} p<.001$.

\subsection{Investigation of Animacy Effect in the Incidental Learning and the Explicit Learning Conditions}

To explore the performance between animate and inanimate items in each condition we carried out logistic (for accuracy) and linear regression (for the exploration of RT) analyses in R. Fixed effects were: Animacy (animate, inanimate), Gender (masculine, feminine), Case (nominative, dative, instrumental, genitive), Block (old, new items), and the interaction between Gender and Case. Participant was included as a random effect to account for variability among the experimental subjects. There was no significant difference in performance on animate versus inanimate items either in comprehension (accuracy and $R T$ ) or production (complete and incomplete production) (see Table 9).

Table 9. Performance on animate vs. inanimate items in comprehension and production

\begin{tabular}{|c|c|c|c|c|c|c|}
\hline \multicolumn{7}{|l|}{ Comprehension } \\
\hline \multirow[b]{2}{*}{ Condition } & \multicolumn{3}{|l|}{ Accuracy } & \multicolumn{3}{|l|}{$R T$} \\
\hline & Std. Error & Wald z & $p$ value & Std. Error & $\mathrm{t}$ value & $p$ value \\
\hline High token frequency & .18 & .17 & .86 & 50.31 & 1.29 & .20 \\
\hline Low token frequency & .18 & -.82 & .41 & 51.44 & 1.05 & .29 \\
\hline Explicit learning & .18 & -1.43 & .15 & 58.94 & -.60 & .55 \\
\hline \multicolumn{7}{|l|}{ Production } \\
\hline & \multicolumn{3}{|c|}{ Complete accuracy } & \multicolumn{3}{|c|}{ Incomplete accuracy } \\
\hline Condition & Std. Error & $\mathrm{z}$ wald & $p$ value & Std. Error & $\mathrm{z}$ wald & $p$ value \\
\hline High token frequency & .25 & -.48 & .63 & .20 & -1.37 & .17 \\
\hline Low token frequency & .27 & 1.21 & .23 & .20 & -1.18 & .86 \\
\hline Explicit learning & .19 & -.79 & .43 & .20 & -.91 & .36 \\
\hline
\end{tabular}

\subsection{Working Memory and Knowledge Acquisition under Different Incidental Learning Conditions}

After having found a significant impact of working memory on receptive (accuracy and $R T$ ) and productive knowledge acquisition (incomplete and compete production of endings) as demonstrated by our analyses using regression models (Tables 6 and 8), we then further carried out a series of two-tailed Pearson correlation tests in each condition to better understand the relationship between participants' scores on the WM tests and the reaction times and accuracy in production and comprehension of the noun-adjective agreement pattern under the incidental learning conditions. Correlations were conducted for two scores arising from both WM tests: OS / RS total score, which was calculated for all the letters recalled by participants in the order they were presented, and OS / RS score, which was calculated for all the letters recalled without taking into account the order. A strong positive correlation between WM and comprehension accuracy was found in the high token frequency condition. 
However, the accuracy scores correlated only with the OS test, but not RS test scores. There was no correlation with comprehension $R T S$ and working memory in either condition.

A positive correlation with WM was also found in this condition in production, both for complete and incomplete endings. The production accuracy scores also correlated with the OS scores. Participants in both incidental learning conditions were found to engage WM in production. A positive correlation was also found in the low token frequency condition. There was a correlation with the RS scores, but not with OS.

Table 10. Correlation with working memory scores

\begin{tabular}{|c|c|c|c|c|c|c|c|c|}
\hline \multicolumn{9}{|c|}{ Comprehension Accuracy } \\
\hline \multirow[t]{2}{*}{ Condition } & \multicolumn{2}{|c|}{ OS total } & \multicolumn{2}{|c|}{ OS score } & \multicolumn{2}{|c|}{ RS total } & \multicolumn{2}{|c|}{ RS score } \\
\hline & $r$ & $p$ & $R$ & $p$ & $r$ & $p$ & $r$ & $p$ \\
\hline Explicit learning & .11 & .66 & -.03 & .92 & .09 & .71 & .23 & .33 \\
\hline High token frequency & .51 & $.02 *$ & .48 & $.03 *$ & .25 & .29 & .11 & .64 \\
\hline Low token frequency & .18 & .46 & .29 & .22 & .12 & .63 & .15 & .54 \\
\hline \multicolumn{9}{|c|}{ Reaction Time Responses } \\
\hline \multirow[t]{2}{*}{ Condition } & \multicolumn{2}{|c|}{ OS total } & \multicolumn{2}{|c|}{ OS score } & \multicolumn{2}{|c|}{ RS total } & \multicolumn{2}{|c|}{ RS score } \\
\hline & $r$ & $p$ & $R$ & $p$ & $r$ & $p$ & $r$ & $p$ \\
\hline Explicit learning & -.13 & .59 & -.08 & .73 & .32 & .17 & .29 & .21 \\
\hline High token frequency & -.13 & .6 & -.18 & .46 & -.22 & .34 & -.28 & .23 \\
\hline Low token frequency & -.04 & .88 & .06 & .81 & .07 & .78 & .16 & .50 \\
\hline \multicolumn{9}{|c|}{ Production of Complete Endings } \\
\hline \multirow[t]{2}{*}{ Condition } & \multicolumn{2}{|c|}{ OS total } & \multicolumn{2}{|c|}{ OS score } & \multicolumn{2}{|c|}{ RS total } & \multicolumn{2}{|c|}{ RS score } \\
\hline & $r$ & $p$ & $R$ & $p$ & $r$ & $p$ & $r$ & $p$ \\
\hline Explicit learning & -.03 & .9 & .04 & .87 & .02 & .94 & .3 & .2 \\
\hline High token frequency & .39 & .09 & .38 & .1 & .01 & .96 & -.07 & .78 \\
\hline Low token frequency & .19 & .42 & .21 & .37 & .43 & .06 & .54 & $.01 *$ \\
\hline \multicolumn{9}{|c|}{ Production of Incomplete Endings } \\
\hline \multirow[t]{2}{*}{ Condition } & \multicolumn{2}{|c|}{ OS total } & \multicolumn{2}{|c|}{ OS score } & \multicolumn{2}{|c|}{ RS total } & \multicolumn{2}{|c|}{ RS score } \\
\hline & $r$ & $p$ & $r$ & $p$ & $r$ & $p$ & $r$ & $p$ \\
\hline Explicit learning & -.07 & .79 & .04 & .85 & .02 & .92 & .3 & .2 \\
\hline High token frequency & .47 & $.04 *$ & .46 & $.04 *$ & .14 & .57 & .04 & .86 \\
\hline Low token frequency & .23 & .34 & .27 & .26 & .48 & $.03 *$ & .59 & $.007 * *$ \\
\hline
\end{tabular}

Note. ${ }^{*} p<.05,{ }^{*} p<.01,{ }^{* * *} p<.001$.

\section{Discussion}

The aim of the experiment was to investigate how the manipulation of noun animacy and token frequency affected the acquisition of receptive and productive knowledge of an L2 grammar, specifically of noun-adjective agreement, under incidental learning conditions. A baseline-comparison explicit learning condition was also included where learners performed significantly better than in the incidental learning conditions, however they were still not at ceiling.

In contrast to the study by Denhovska et al. (2016), where there was a potentially facilitating correspondence between the grammatical gender of the animate nouns and the natural gender of the referents, in this experiment we used animate nouns denoting animals-epicenes where there was no obvious correspondence between grammatical and natural genders. Our first finding was that the absence of a natural gender cue affected learning even for receptive knowledge: performance in comprehension was at chance and slightly above chance levels, but not at ceiling, as in all conditions in Denhovska et al. (2016). In production, even in the explicit learning condition the performance on the pattern without obvious gender marking - where the morphological paradigm in masculine or feminine gender could not be easily associated with the male or female referent, as the head noun did not reflect the biological gender of the item in English) - was below chance (complete production) and slightly above chance (incomplete production). In a similar set-up in Denhovska et al. (2016) performance was above chance in the explicit learning condition on the pattern with an obvious semantic gender marker - on the pattern where the head nouns denoted a referent of either masculine or feminine natural gender, such as magician or witch.

With regards to frequency effects, high token frequency had a stronger impact on productive knowledge acquisition via incidental learning than low token frequency. In line with research on L1 acquisition, we assume 
that learners were guided by exemplar-based learning and entrenchment in production (Braine \& Brooks, 1995; Brooks, Tomasello, Dodson, \& Lewis, 1999; N. Ellis, 2006; Tomasello, 2000, 2008).

Generally, it was found that animacy did not have a significant effect on knowledge retention either in production or in comprehension. In linguistics and cognitive psychology animacy is viewed as a salient feature, which has a strong effect on grammar categories in language (the animacy hierarchy from personal pronouns at the top to inanimate nouns at the bottom (Corbett, 2000; Croft, 1990; Yamamoto, 1999), with animals being considered lower on the hierarchical scale than humans (Zaenen et al., 2004)), as well as on perception (animate entities being more easily identifiable by the brain due their characteristics of motion (Schultz, Friston, O'Doherty, Wolpert, \& Frith, 2005)). Cognition research that investigated the impact of animate (unpredictable) motion and inanimate (predictable) motion on perception in adults demonstrated that animate entities are perceived faster than inanimate ones, due to better capturing the attention of the experimental subjects (Pratt, Radulescu, Guo, \& Abrams, 2014). Similarly, memory research indicated that linguistic items (nouns and non-words) denoting animate entities were memorized and processed faster than the ones denoting inanimate objects (VanArsdall et al., 2013, 2014). Second language acquisition research also showed that animacy had an effect on L2 processing (Jackson \& Roberts, 2010).

According to these findings, if animacy had an effect on knowledge acquisition under incidental learning conditions, we should have observed a difference between the two animacy levels, with agreement containing animate (animals-epicenes) as head nouns being recognized / produced faster and more accurately. However, no difference between the processing of gender agreement in animate and inanimate head nous was found in the current study. Because we chose epicenes, our participants could not rely on any semantic cues in determining whether a noun was masculine or feminine; their only cues were morphological. Belacchi \& Cubelli (2012) showed a revealing cross-linguistic difference between Italian and English speakers that is pertinent to the role of morphology in gender categorization and is relevant to our findings. In their studies only Italian speakers- both children and adults - were successful in categorizing epicenes as either masculine or feminine; the English speakers performed at chance. Unlike English speakers, who only had access to natural gender cues, Italian speakers had access to morpho-syntactic cues on noun endings and articles in the vast majority of instances; this grammatical information was what the Italian speakers used in their categorization task. The fact that animacy effect, as a salient feature for knowledge acquisition, was not observed in our study suggests that participants were able to detect the morpho-syntactic patterns of endings co-occurring together and generalize the knowledge acquired at one animacy level (stereotypical characters of male and female gender) during pre-training to other animacy levels (animals-epicenes and objects) during training. Therefore, this is consistent with the hypothesis that adults were guided by morpho-syntactic cues during incidental exposure to the stimuli rather than by animacy cues or their own intuitive assumptions about gender.

The third finding was that learners relied on WM in the high token frequency condition of the incidental learning paradigm. These findings are in line with previous research showing that verbal working memory was involved in learning of words through incidental exposure in the absence of facilitating factors, such as visual cues (Duyck, Szmalec, Kemps, \& Vandierendonck, 2003). In the present study one of the facilitating cues, which was taken away from the learners in comparison to Denhovska et al. (2016), was the match between natural and grammatical gender. In our previous study learners were able to build associations between the morphological patterns (feminine/masculine grammatical gender expressed by a discrete paradigm of endings for masculine vs. feminine gender) and the explicitly marked biological gender of the referent (e.g., magician/witch). In the present study, however, the learners were not able to build such associations, since the referents (animate: animals-epicenes, inanimate: objects) were not associated with these extra natural gender cues. Thus, whatever learning occurred under incidental exposure, if any, could be based only on noticing the changes on morphological endings and building on those. This would explain the null animacy effect found in the present study, in contrast to previous research (Antón-Méndez, 1999; Vigliocco \& Franck, 1999; Finnemann, 1992). It is rather a biological gender marker than a perceptually salient feature of a referent being animate or inanimate (VanArsdall et al., 2013, 2014) that affects learning of gender agreement morphology. Positive effect of animacy found in gender agreement research (Alarcon, 2009; Vigliocco \& Franck, 1999) therefore may be not purely due to animacy, but due to the semantic gender marking (feminine, masculine) in such animate nouns (e.g., esposo "male spouse"/esposa "female spouse"), which facilitates processing. In addition, humans are considered more prominent for grammatical processing, especially in languages with richer morphology than English, due to being placed higher on the accessibility scale. Since in our experiment we used as stimuli animals (mammals - higher animals (Yamamoto, 1999)) that are placed lower than humans on such hierarchy and thus have lower accessibility, this fact may also partially contribute to the null animacy effect (Zaenen et al., 2004). 
The correlation with WM in the present experiment, not only in production, but also in comprehension in the high token frequency condition, flags the processing cost involved in computing the agreement pattern in the absence of an additional semantic information converging on the same gender cue and thus facilitating learning. Moreover, in the high token frequency condition there was a correlation with OS test scores rather than with RS scores, which would suggest that, instead of simply activating automatic knowledge, a learner had to perform some knowledge manipulation. During language processing different WM and executive functions may be engaged (Linck et al., 2013), but little is yet known about what exactly these functions are and how they are involved; we propose that the correlation with OS found in this study indicates that the processes of maintenance, updating and shifting are engaged during knowledge acquisition in a condition where a learner is incidentally exposed to a high number tokens of the target structure (Miyake et al., 1999; Miyake \& Friedman, 2012). Thus, such a correlation suggests effortful learning and the attempt of a learner to "make sense" of the knowledge initially tapped implicitly under the incidental learning conditions. Previous research focusing on knowledge acquisition under incidental versus rule-search conditions found a correlation with OS in the rule-search condition - where a learner is intentionally aimed at figuring out the rules in the stimulus input - but not in the incidental learning condition (Tagarelli et al., 2011). No such correlation was found in any of the incidental learning conditions in Denhovska et al. (2016), where learners were exposed to the same pattern as in the present experiment, but with the additional information provided by natural gender. A correlation was instead found with RS. Similarly, in the present experiment in the low token frequency condition, production accuracy correlated with RS scores, which may indicate an automatic semantic processing rather than manipulation of the acquired knowledge. In this condition learners also relied on WM in production, but the correlation with the RS test may be an indicator of engagement of different types of WM resources compared to the conditions where a correlation with the OS test was found. As suggested by MacDonald \& Christiansen (2002), RS tasks tap into experience-based language processing skills in addition to memory. Thus, the correlation with RS found in the present experiment may indicate procedural processes taking place. Future research should shed more light on the issue of what WM resources are being engaged during learning under incidental and explicit learning conditions. Another issue to explore is the role of proficiency and its correlation with the learners' sensitivity to the noun animacy during learning such an agreement pattern. One possibility would be to conduct a longitudinal study to explore the gradual change in the effect of these factors. Such as study, if conducted in the settings of a classroom might provide an opportunity to better understand the role of animacy, frequency and WM, and could inform second language learning and teaching practices by indicating how learners of an ungendered language acquire gender agreement rules in a language with highly inflectional morphology.

\section{Acknowledgments}

I would like to thank Prof. Serratrice and Prof. Payne for their help during conducting the study and the manuscript preparation.

\section{References}

Abbot-Smith, K., Lieven, E., \& Tomasello, M. (2004). Training 2; 6-year-olds to produce the transitive construction: The role of frequency, semantic similarity and shared syntactic distribution. Developmental Science, 7(1), 48-55. http://dx.doi.org/10.1111/j.1467-7687.2004.00322.x

Alarcon, I. (2009). The processing of gender agreement in L1 and L2 Spanish: Evidence from reaction time data. Hispania, 92(4), 814-828.

Alptekin, C., \& Ercetin, G. (2009). Assessing the relationship of WM to L2 reading: Does the nature of comprehension process and reading span task make a difference? System, 37(2), 627-639. http://dx.doi.org/10.1016/j.system.2009.09.007

Baddeley, A., \& Logie, R. (1999). Working memory: The multicomponent model. In A. Miyake \& P. Shah (Eds.), Models of working memory (pp. 28-61). Cambridge: Cambridge University Press. http://dx.doi.org/10.1017/CBO9781139174909.005

Belacchi, C., \& Cubelli, R. (2012). Implicit knowledge of grammatical gender in preschool children. Journal of Psycholinguistic Research, 41(4), 295-310. http://dx.doi.org/10.1007/s10936-011-9194-y

Bonin, P., Gelin, M., \& Bugaiska, A. (2014). Animates are better remembered than inanimates: Further evidence from word and picture stimuli. Memory and Cognition, 42(3), 370-382. http://dx.doi.org/10.3758/s13421-013-0368-8

Braine, M., \& Brooks, P. (1995). Verb argument structure and the problem of avoiding an overgeneral grammar. In M. Tomasello \& W. Merriman (Eds.), Beyond names for things: Young children's acquisition of verbs (pp. 
352-376). Hillsdale, NJ: Erlbaum.

Brooks, P., \& Kempe, V. (2013).Individual differences in adult foreign language learning: The mediating effect of metalinguistic awareness. Memory \& Cognition, 41(2), 281-296. http://dx.doi.org/10.3758/s13421-012-0262-9

Brooks, P., Tomasello, M., Dodson, K., \& Lewis, L. (1999). Young children's overgeneralizations with fixed transitivity verbs. Child Development, 70(6), 1325-1337. http://dx.doi.org/10.1111/1467-8624.00097

Bruhn de Garavito, J., \& White, L. (2002). L2 acquisition of Spanish DPs: The status of grammatical features. In A. Perez-Leroux \& J. Liceras (Eds.), The acquisition of Spanish morphosyntax: The L1/L2 connection (pp. 153-178). Dordrecht: Kluwer. http://dx.doi.org/10.1007/978-94-010-0291-2_6

Corbett, G. (2000). Number. Cambridge: Cambridge University Press. http://dx.doi.org/10.1017/CBO9781139164344

Croft, W. (1990). Typology and Universals. Cambridge: Cambridge University Press.

DeKeyser, R. (1995). Learning second language grammar rules: An experiment with a miniature linguistic system. Studies in Second Language Acquisition, 17(3), 379-410. http://dx.doi.org/10.1017/S027226310001425X

Denhovska, N., Serratrice, L., \& Payne, J. (2016). Acquisition of second language grammar under incidental learning conditions: The role of frequency and working memory. Language Learning, 66(1), 159-190. http://dx.doi.org/10.1111/lang.12142

Duyck, W., Szmalec, A., Kemps, E., \& Vandierendonck, A. (2003). Verbal WM is involved in associative word learning unless visual codes are available. Journal of Memory and Language, 48(3), 527-541. http://dx.doi.org/10.1016/S0749-596X(02)00533-8

Ellis, N. (2002). Frequency effects in language processing: A review with implications for theories of implicit and explicit language acquisition. Studies in Second Language Acquisition, 24(2), 143-188. http://dx.doi.org/10.1017/S0272263102002024

Ellis, N. (2006). Cognitive perspectives on SLA: The associative-cognitive CREED. AILA Review, 19(22), 100-121.

Fernandez-Garcia, M. (1999). Patterns of gender agreement in the speech of secondlanguage learners. In J. Gutierrez-Rexach \& F. Martınez-Gil (Eds.), Advances inHispanic linguistics: Papers from the 2nd Hispanic linguistics symposium (pp. 3-15). Somerville, MA: Cascadilla Press.

Finnemann, M. (1992). Learning agreement in the noun phrase: The strategies of three first-year Spanish students. IRAL, 30(2), 121-136. http://dx.doi.org/10.1515/iral.1992.30.2.121

Gass, S., \& Mackey, A. (2002). Frequency effects and second language acquisition. Studies in Second Language Acquisition, 24(2), 249-260. http://dx.doi.org/10.1017/S0272263102002097

Hargreaves, I., Pexman, P., Johnson, J., \& Zdrazilova, L. (2012). Richer concepts are better remembered: Number of features effects in free recall. Frontiers in Human Neuroscience, 6(73), 1-11. http://dx.doi.org/10.3389/fnhum.2012.00073

Harrington, M., \& Sawyer, M. (1992). L2 WM capacity and L2 reading skill. Studies in Second Language Acquisition, 14(1), 25-38. http://dx.doi.org/10.1017?S0272263100010457

Hummel, K. (2009). Aptitude, phonological memory, and second language proficiency in nonnovice adult learners. Applied Psycholinguistics, 30(2), 225-249. http://dx.doi.org/10.1017/S0142716409090109

Jackson, C., \& Roberts, L. (2010). Animacy affects the processing of subject-object ambiguities in the second language: Evidence from self-paced reading with German second language learners of Dutch. Applied Psycholinguistics, 31(4), 671-691. http://dx.doi.org/10.1017/S0142716410000196

Juffs, A. (2004). Representation, processing and WM in a second language. Transactions of the Philological Society, 102(2), 199-225. http://dx.doi.org/10.1111/j.0079-1636.2004.00135.x

Kempe, V., Brooks, P., \& Kharkhurin, A. (2010). Cognitive predictors of generalization of Russian grammatical gender categories. Language Learning, 60(1), 127-153. http://dx.doi.org/10.1111/j.1467-9922.2009.00553.x

Kidd, E., Lieven, E., \& Tomasello, M. (2006). Examining the role of lexical frequency in children's acquisition and processing of sentential complements. Cognitive Development, 21(2), 93-107. http://dx.doi.org/10.1016/j.cogdev.2006.01.006 
Kidd, E., Lieven, E., \& Tomasello, M. (2010). Lexical frequency and exemplar-based learning effects in language acquisition: Evidence from sentential complements. Language Sciences, 32(1), 132-142. http://dx.doi.org/10.1016/j.langsci.2009.05.002

Kirchner, H., \& Thorpe, S. (2006). Ultra-rapid object detection with saccadic eye movements: Visual processing speed revisited. VisionResearch, 46(11), 1762-1776. http://dx.doi.org/10.1016/j.visres.2005.10.002

Lee, J. (2002). The incidental acquisition of Spanish. Studies in Second Language Acquisition, 24(1), 55-80. http://dx.doi.org/10.1017/S0272263102001031

Leeser, M. (2007). Learner-based factors in L2 reading comprehension and processing grammatical form: Topic $\begin{array}{llll}\text { familiarity } \quad \text { and } & \text { LM. }\end{array}$ http://dx.doi.org/10.1111/j.1467-9922.2007.00408.x

Leung, J., \& Williams, J. (2011). The implicit learning of mappings between forms and contextually derived meanings. Studies in Second Language Acquisition, 33(1), 33-55. http://dx.doi.org/10.1017/S0272263110000525

Lieven, E., \& Tomasello, M. (2008). Children's first language acquisition from a usage-based perspective. In P. Robinson \& N. Ellis (Eds.), Handbook of Cognitive Linguistics and Second Language Acquisition (pp. 168-196). New York: Routledge.

Linck, J., Hughes, M., Campbell, S., Silbert, N., Tare, M., Jackson, S., \& Doughty, C. (2013). Hi-LAB: A new measure of aptitude for high-level language proficiency. Language Learning, 63(3), 530-566. http://dx.doi.org/10.1111/lang.12011

Lipp, O., Derakshan, N., Waters, A., \& Logies, S. (2004). Snakes and cats in the flower bed: Fast detection is not specific to pictures of fear-relevant animals. Emotion, 4(3), 233-250. http://dx.doi.org/10.1037/1528-3542.4.3.233

MacDonald, M., \& Christiansen, M. (2002). Reassessing working memory: Comment on Just and Carpenter (1992) and Waters and Caplan (1996). Psychological Review, 109(1), 35-54. http://dx.doi.org/10.1037/0033-295X.109.1.35

Masoura, E., \& Gathercole, S. (2005). Contrasting contributions of phonological short-term memory and long-term knowledge to vocabulary learning in a foreign language. Memory, 13(4), 422-429.

Matthews, D., Lieven E., Theakston, A., \& Tomasello, M. (2005). The role of frequency in the acquisition of English word $\quad$ order. Cognitive Development, 20(1), 121-136. http://dx.doi.org/10.1016/j.cogdev.2004.08.001

Miyake, A., \& Friedman, N. (2012). The nature and organization of individual differences in executive functions: Four general conclusions. Current Directions in Psychological Science, 21(1), 8-14. http://dx.doi.org/10.1177/0963721411429458

Miyake, A., Friedman, N., Emerson, M., Witzki, A., Howerter, A., \& Wager, T. (1999). The unity and diversity of executive functions and their contributions to complex "frontal lobe" tasks: A latent variable analysis. Cognitive Psychology, 41(1), 49-100. http://dx.doi.org/10.1006/cogp.1999.0734

Morgan-Short, K., Sanz, C., Stainhauer, K., \& Ullman, M. (2010). Second language acquisition of gender agreement in explicit and implicit training conditions: An event-related potential study. Language Learning, 60(1), 154-193. http://dx.doi.org/10.1111/j.1467-9922.2009.00554.x

New, J., Cosmides, L., \& Tooby, J. (2007). Category specific attention for animals reflects ancestral priorities, not expertise. Proceedings of the National Academy of Sciences, 104(42), 16598-16603. http://dx.doi.org/10.1073/pnas.0703913104

Norris, J., \& Ortega, L. (2000). Effectiveness of L2 instruction: A research synthesis and quantitative meta-analysis. Language Learning, 50(3), 417-528. http://dx.doi.org/10.1111/0023-8333.00136

Öhman, A., Flykt, A., \& Esteves, F. (2001). Emotion drives attention: Detecting the snake in the grass. Journal of Experimental Psychology: General, 130(3), 466-478. http://dx.doi.org/10.1037/0096-3445.130.3.466

Öhman, A., Lundqvist, D., \& Esteves, F. (2001). The face in the crowd revisited: A threat advantage with schematic stimuli. Journal of Personality and Social Psychology, 80(3), 381-396. http://dx.doi.org/10.1037/0022-3514.80.3.381

Opfer, J., \& Gelman, S. (2011). Development ofthe animate-inanimate distinction. In U. Goswami (Ed.), The 
Wiley-Blackwell handbook of childhood cognitive development (2nd ed., pp. 213-238). Oxford: Wiley-Blackwell.

Pratt, J., Radulescu, P., Guo, R., \& Abrams, R. (2014). It's alive! Animate motion captures visual attention. Psychological Science, 21(11), 1724-1730. http://dx.doi.org/10.1177/0956797610387440

Rebuschat, P., \& Williams, J. (2012). Implicit and explicit knowledge in second language acquisition. Applied Psycholinguistics, 33(4), 1-28.

Robinson, P. (1996). Learning simple and complex second language rules under implicit, incidental, rule-search and instructed conditions. Studies in Second Language Acquisition, 18(1), 27-67. http://dx.doi.org/10.1017/S0272263100014674

Robinson, P. (2005). Cognitive abilities, chunk-strength, and frequency effects in implicit artificial grammar and incidental L2 learning: Replications of Reber, Walkenfeld, and Hernstadt (1991) and Knowlton, and Squire (1996) and their relevance for SLA. Studies in Second Language Acquisition, 27(2), 235-268. http://dx.doi.org/10.1017/S0272263105050126

Sagarra, N., \& Herschensohn, J. (2010). The role of proficiency and working memory in gender and number agreement processing in L1 and L2 Spanish. Lingua, 120(8), 2022-2039. http://dx.doi.org/10.1016/j.lingua.2010.02.004

Sagarra, N., \& Herschensohn, J. (2011). Proficiency and animacy effects on L2 gender agreement processes during comprehension. $\quad$ Language $\quad$ Learning, $\quad 61(1), \quad 80-116$. http://dx.doi.org/10.1111/j.1467-9922.2010.00588.x

Sagarra, N., \& Herschensohn, J. (2012). Processing of gender and number agreement in late Spanish bilinguals. International Journal of Bilingualism, 17(5), 607-627. http://dx.doi.org/10.1177/1367006912453810

Sagarra, N., (2007). Online processing of gender agreement in low proficient English-Spanish late bilinguals. In M. Cabrera, J. Camacho, V. Deprez, N. Flores, \& L. Sanchez (Eds.), Current Issues in Linguistic Theory Series (pp. 240-253). Amsterdam: John Benjamins. http://dx.doi.org/10.1075/cilt.287.18sag

Schultz, J., Friston, K., O’Doherty, J., Wolpert, D., \& Frith, C. (2005). Activation in posterior superior temporal sulcus parallels parameter inducing the perception of animacy. Neuron, 45(4), 625-635. http://dx.doi.org/10.1016/j.neuron.2004.12.052

Speciale, G., Ellis, N., \& Bywater, T (2004). Phonological sequence learning and short-term store capacity determine second language vocabulary acquisition. Applied Psycholinguistics, 25(2), $293-321$. http://dx.doi.org/10.1017/S0142716404001146

Tagarelli, K., Borges Mota, M., \& Rebuschat, P. (2011). The role of working memory in the implicitand explicit language learning. In L. Carlson, C. Hölscher, \& T. Shipley (Eds.), Proceedings of the 33rd Annual Conference of the Cognitive Science Society (pp. 2061-2066). Austin, TX: Cognitive Science Society.

Tomasello, M. (2000). The item-based nature of children's early syntactic development. Trends in Cognitive Sciences, 4(4), 156-163. http://dx.doi.org/10.1016/S1364-6613(00)01462-5

Tomasello, M. (2003). Constructing a language: a usage-based theory of language acquisition. Cambridge: Harvard University Press.

Tomasello, M. (2008). Origins of human communication. Cambridge: The MIT Press.

Unsworth, N., Heitz, R., Schrock, J., \& Engle, R. (2005). An automated version of the operation span task. Behavior Research Methods, 37(3), 498-505. http://dx.doi.org/10.3758/BF03192720

VanArsdall, J., Nairne, J., Pandeirada, J., \& Blunt, J. (2013). Adaptive memory: Animacy processing produces $\begin{array}{lllll}\text { mnemonic } & \text { advantages. } & \text { Experimental } & \text { 172-178. }\end{array}$ http://dx.doi.org/10.1027/1618-3169/a000186

VanArsdall, J., Nairne, J., Pandeirada, J., \& Cogdill, M. (2014). Adaptive memory: Animacy effects persist in paired-associate learning. Memory, 23(5), 657-663. http://dx.doi.org/10.1080/09658211.2014.916304

Vigliocco, G., \& Franck, J. (1999). When sex and syntax go hand in hand: Gender agreement in language production. Journal of Memory and Language, 40(4), 455-478. http://dx.doi.org/10.1006/jmla.1998.2624

Williams, J., \& Lovatt, P. (2003). Phonological memory and rule learning. Language Learning, 53(1), 67-121. http://dx.doi.org/10.1111/1467-9922.00211

Yamamoto, M. (1999). Animacy and Reference: A Cognitive Approach to Corpus Linguistics. Amsterdam: John 
Benjamins. http://dx.doi.org/10.1075/slcs.46

Yang, J., \& Li, P. (2012). Brain Networks of explicit and implicit learning. PLOSONE, 7(8), 1-9. http://dx.doi.org/10.1371/journal.pone.0042993

Yang, J., Wang, A., Yan, M., Zhu, Z., Chen, C., \& Wang, Y. (2012). Distinct processing for pictures of animals and objects: Evidence from eye movements. Emotion, 12(3), 540-551. http://dx.doi.org/10.1037/a0026848

Zaenen, A., Carletta, J., Garretson, G., Bresnan, J., Koontz-Garboden, A., Nikitina, T., ... O’Connor, M. (2004). Animacy encoding in English: Why and how. In D. Byron \& B. Webber (Eds.), Proceedings of the ACL Workshop on Discourse Annotation, Barcelona (pp. 118-125). Stroudsburg, PA: Association for Computational Linguistics. http://dx.doi.org/10.3115/1608938.1608954

\section{Note}

Note 1. There was no significant difference between performance on old and new items in production in either condition; in comprehension, in both incidental learning conditions participants responded significantly slower to new items (high token frequency: $p<.001$; low token frequency: $p=.04$ ), but not less accurately.

\section{Appendix A}

\section{Vocabulary Learning Items}

\begin{tabular}{lll}
\hline Nouns & Adjectives & Prepositions \\
\hline belka-squirrel & jeltiy-yellow & Idu k...-I am going towards \\
chainik-kettle & krasniy-red & Idu s... -I am going with \\
chashka-cup & cherniy-black & Idu ot... -I am going from \\
kniga-book & seriy-grey & \\
lisa-fox & & \\
slon-elephant & & \\
\hline
\end{tabular}

\section{AppendixB}

\section{Experimental Stimuli}

\section{Pre-training sentences}

Eto krasniy volshebnik (This is a red magician)

Idu k krasnomu volshebniku

Idu s krasnim volshebnikom

Idu ot krasnogo volshebnika

Eto nizkaya vedma (This is a short witch)

Idu k nizkoy vedme

Idu s nizkoy vedmoy

Idu ot nizkoy vedmi

\section{Training sentences}

Masculine gender

\section{Objects}

Eto ostriy noj (This is a sharp knife)

Idu k ostromu noju

Idu s ostrim nojom

Idu ot ostrogo noja 
Eto jeltiy chainik (This is a yellow kettle)

Idu $\mathrm{k}$ jeltomu chainiku

Idu s jeltim chainikom

Idu ot jeltogo chainika

Eto seriy utyug (This is a grey iron)

Idu k seromu utyugu

Idu s serim utyugom

Idu ot serogo utyuga

Animals-epicenes

Eto beliy krolik (This is a white rabbit)

Idu kbelomu kroliku

Idusbelim krolikom

Idu ot belogo krolika

Eto krupniy slon (This is a big elephant)

Idu k krupnomu slonu

Idu s krupnim slonom

Idu ot krupnogo slona

Eto tolstiy bobr (This is a fat beaver)

Idu $\mathrm{k}$ tolstomu bobru

Isu s tolstim bobrom

Idu ot tolstogo bobra

Feminine gender

Objects

Eto staraya kniga (This is an old book)

Idu k staroy knige

Idu s starloy knigoy

Idu ot staroy knigi

Eto krasnaya chashka (This is a red cup)

Idu k krasnoy chashke

Idu s krasnoy chashkoy

Idu ot krasnoy chashki

Eto tonkaya svecha (This is a thin candle)

Idu k tonkoy sveche

Idu s tonkoy svechoy

Idu ot tonkoy svechi 


\section{Animals-epicenes}

Eto mokraya vidra (This is a wet otter)

Idu k mokroy vidre

Idu s mokroy vidroy

Idu ot mokroy vidre

Eto hudaya lisa (This is a thin fox)

Idu k hudoy lise

Idu s hudoy lisoy

Idu ot hudoy lisi

Eto malaya belka (This is a small squirrel)

Idu k maloy belke

Idu s maloy belkoy

Idu ot maloy belki

\section{Copyrights}

Copyright for this article is retained by the author(s), with first publication rights granted to the journal.

This is an open-access article distributed under the terms and conditions of the Creative Commons Attribution license (http://creativecommons.org/licenses/by/4.0/). 